\title{
Коррозионная стойкость уртитов в жидких агрессивных средах
}

\author{
Белогурова Т.П. ${ }^{1}$, Нерадовский Ю.Н. ${ }^{2}$, Компанченко А.А. ${ }^{2}$ \\ ${ }^{1}$ Институт химии и технологии редких элементов и минерального сырья им. И.В. Тананаева \\ КНЦPAH, Anamumbl, belog_tp@chemy.kolasc.net.ru \\ ${ }^{2}$ Геологический институт КНЦРАН, Anamumbl,nerad@geoksc.apatity.ru
}

Аннотация. В работе приведены исследования по изучению состава, структуры и свойств уртитов рудника «Восточный». Установлено, что данные породы относятся к плотным и прочным, с низкими значениями водопоглощения и истираемости и могут служить сырьевым источником заполнителей для тяжелых бетонов. Препятствием для применения данных пород в строительстве является повышенное содержание в их составе нефелина, относящегося к вредным примесям. Исследованиями щебня из уртитов показано, что он соответствует маркам по прочности M1000, по истираемости И-II, по морозостойкости F200, что позволяет использовать его в качестве заполнителей бетонов. В работе проведены исследования коррозионной стойкости уртитов и заполнителей на их основе в различных агрессивных средах. Результаты испытаний уртитов и уртитового щебня в средах с повышенным содержанием ионов $\mathrm{Cl}^{-}, \mathrm{SO}_{4}{ }^{2-}$ и $\mathrm{NO}_{3}$ - свидетельствуют о достаточной стойкости этих материалов в жидких агрессивных средах. Микроскопическими исследованиями структуры уртитов после испытаний установлено, что в образцах следов растворения минералов не наблюдается и признаков коррозии породы не обнаружено.

Ключевые слова: вскрышные породы, уртит, свойства, коррозионная стойкость, жидкие агрессивные среды, микроскопические исследования.

\section{Corrosion resistance of urtites in aggressive media}

\author{
Belogurova T.P. ${ }^{1}$, Neradovsky Y.N. ${ }^{2}$, Kompanchenko A.A. ${ }^{2}$ \\ ${ }^{1}$ I.V.Tananaev Institute of Chemistry and Technology of Rare Elements and Mineral Raw Materials of the Kola \\ Science Centre, RAS, Apatity, belog_tp@chemy.kolasc.net.ru \\ ${ }^{2}$ Geological Institute of the Kola Science Centre, RAS, Apatity,nerad@geoksc.apatity.ru
}

\begin{abstract}
The paper presents studies on the composition, structure and properties of urtites of the Vostochny mine. It is established that these rocks are dense and strong, with low values of water absorption and abrasion and can serve as a raw source of aggregates for heavy concrete. The use of these rocks in construction is constrained by the increased content of nepheline in their composition, which is related to harmful impurities. Research of crushed stone from urtites shows that it corresponds to the brands of strength M1000, abrasion resistance I-II, frost resistance F200, which allows it to be used as aggregates of concrete. In this work studies on the corrosion resistance of urtites and fillers on their basis in various aggressive environments are carried out. The results of tests of urtites and urtite crushed stone in environments with a high content of $\mathrm{Cl}^{-}, \mathrm{SO}_{4}{ }^{2-}$ and $\mathrm{NO}_{3}^{-}$ions indicate sufficient resistance of these materials in liquid corrosive environments. Microscopic studies of the structure of urtites after testing show that no traces of dissolution of minerals in the samples are observed and no signs of corrosion of the rock are found.
\end{abstract} research.

Key words: overburden rocks, urtite, properties, corrosion resistance, liquid aggressive media, microprobe

Предприятия Кольского горнопромышленного комплекса производят свыше 60 \% продукции промышленного производства области. При этом они являются основными источниками образования отходов. Только в 2017 г. образовалось почти 211 млн. т отходов горнодобывающей промышленности, что составляет 99.9 \% от всех видов отходов производства в области. Общая площадь загрязненных земель составляет около 19250 км² или 22 \% Мурманской области (Доклад о состоянии.., 2017).

Одним из примеров нетрационального природопользования в Кольском регионе является практически не используемые вскрышные породы рудников АО «Апатит». Препятствием для применения данных пород в строительстве является повышенное содержание в их составе нефелина, относящегося к вредным примесям. Ранее проведенные исследования вскрышных пород позволи- 
ли рекомендовать их для получения бетонных изделий, эксплуатирующихся в неагрессивных условиях (Белогурова Т.П., Крашенинников О.Н., 2004). В представленной работе приводятся исследования поведения нефелинсодержащих пород - уртитов и уртитового щебня в различных агрессивных средах с целью научного обоснования возможности их использования для получения бетонов.

Уртиты представляют собой серовато-зеленые породы средне-крупнозернистого и пегматоидного сложения. Главные минеральные фазы пород - нефелин, пироксен, полевой шпат. В породах постоянно присутствуют также сфен, апатит, амфибол, биотит, титаномагнетит и акцессории: эвдиалит, лампрофиллит, энигматит, содалит, пектолит, ринколит (рис. 1). Минеральный состав уртитов представлен в таблице 1.

Таблица 1. Минеральный состав уртитов.

Table 1. Mineral composition of urtites.

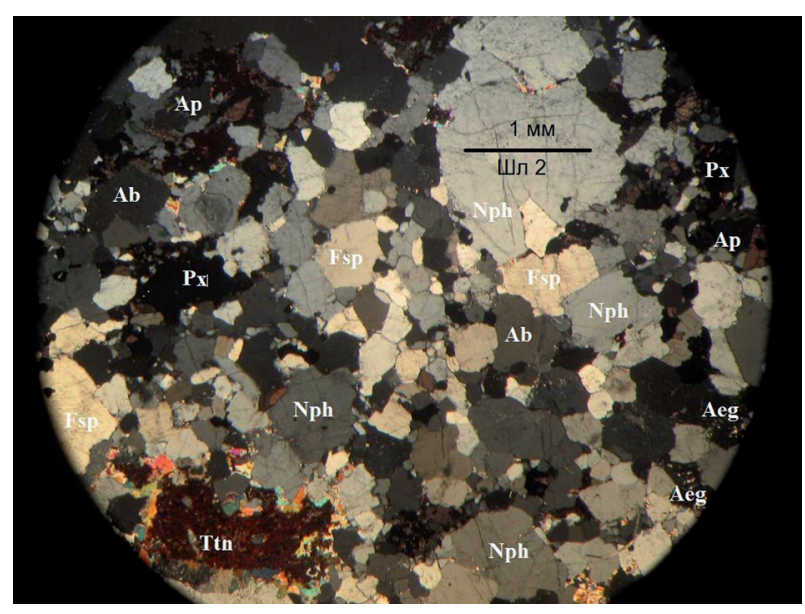

Рис.1. Микроструктура уртита.

Fig.1. Microstructure of urtite.

\begin{tabular}{|l|c|}
\hline Минерал & Содержание, мас. \% \\
\hline Нефелин & $70.4-76.8(71.3)$ \\
\hline Пироксен & $14.8-17.5(16.4)$ \\
\hline Полевой шпат & $5.7-7.9(6.2)$ \\
\hline Сфен & $2.2-3.5(2.8)$ \\
\hline Апатит & $0.5-1.3(0.7)$ \\
\hline Титаномагнетит & $0.2-0.9(0.5)$ \\
\hline Слюда & $0.05-0.3(0.1)$ \\
\hline Содалит & $0.3-1.1(0.5)$ \\
\hline Натролит & $0.3-1.5(0.7)$ \\
\hline Прочие & $0.05-0.9(0.8)$ \\
\hline
\end{tabular}

Уртиты характеризуются выдержанностью минерального состава. Среднее содержание основных породообразующих минералов в породах - нефелина, пироксена и полевого шпата составляет $71.3,16.4$ и $6.2 \%$, соответственно.

Результаты физико-механических испытаний уртитов показали, что данные породы отно-

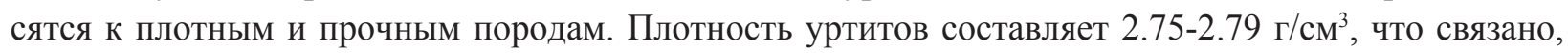
по-видимому, с большим содержанием в уртитах таких плотных минералов, как эгирин и титаномагнетит. Низкие значения пористости (0.40-2.2 \%) и водопоглощения (0.10-0.15 \%) пород также свидетельствуют об их хорошей сохранности и плотности. Предел прочности при сжатии образцовкернов уртитов достаточно высок - не ниже 160 МПа, достигая максимального значения 230 МПа. Сопротивление ударным воздействиям, определенное на копре «Пэджа», составляет не менее 70 см, что позволяет отнести исследованные породы к группе прочных пород. Истираемость уртитов низкая и не превышает 0.20 г/ $\mathrm{cm}^{2}$. Таким образом, данные вскрышные породы характеризуются сравнительно высокими физико-механическими свойствами.

Испытания заполнителей показали, что насыпная плотность щебня из уртитов составляет

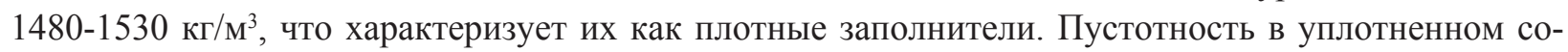
стоянии, зависящая в основном от формы зерен заполнителей, составляет 44.8-46.6 \%, что свидетельствует о хорошей уплотняемости щебня. Водопоглощение заполнителей низкое и составляет от $0.3 \%$ у крупных фракций до 1.9 \% у мелких, что указывает на высокое качество щебня. Качественные характеристики щебня, включающие показатели содержания пластинчатых зерен, слабых зерен, пылевидных частиц соответствуют требованиям, предъявляемым к щебню высшей категории качества. Показатели дробимости уртитов находятся в пределах от 16.7-18.8 \%, что соответствует марке щебня по прочности 1000. Потеря массы щебня из уртита при испытаниях в полочном барабане составила от 27.2 до 30.5 \%, что соответствует марке по истираемости И-ІІ. Испытания щебня на морозостойкость, проведенные ускоренным способом в растворе сернокислого натрия, показали, что наибольшие потери массы после 15 циклов составили всего 2.9 \%, т.е. щебень из уртита всех 
фракций соответствует марке по морозостойкости F200. Испытания также показали устойчивость структуры щебня против всех видов распадов. Таким образом, заполнители на основе уртита рудника «Восточный» соответствуют основным требованиям ГОСТ 8267-93 и могут быть использованы для строительных работ. Мелкий заполнитель соответствующего зернового состава также отвечает требованиям ГОСТ 8736-2014 на песок для строительных работ.

В работе были проведены исследования коррозионной стойкости уртитов и заполнителей на их основе в различных агрессивных средах.

При выборе агрессивных сред в лабораторных условиях руководствовались оценкой коррозионной стойкости уртитов и заполнителей в растворах, имитирующих жидкие среды, аналогичные рудничным водам, но с повышенным содержанием агрессивных составляющих.

Главными химическими составляющими рудничных вод являются сульфаты, нитраты и хлориды. Для проведения исследований в лабораторных условиях были выбраны 3 среды с наиболее распространенными в сточных водах химическими элементами, концентрацию которых увеличили в 100 раз: сульфатная с концентрацией ионов $\mathrm{SO}_{4}^{2-}=1500$ мг/л, азотнокислая с концентрацией ионов $\mathrm{NO}_{3}^{--}=3500$ мг/л и хлористая с концентрацией ионов $\mathrm{CI}^{-}=150$ мг/л. В качестве неагрессивной среды применяли дистиллированную воду.

Для контроля за изменением массы образцов при воздействии агрессивных сред с течением времени из уртита были изготовлены и взвешены 20 кубиков с ребром 40 мм (по 5 штук для каждой среды). Средняя масса 5 образцов для каждой среды составляла для I - 188.80 г., для II - 191.13 г., для III - 196.30 г. и для IV - 188.52 г.

Прочностные испытания уртита проводились на образцах-кубиках с ребром 25 мм. Перед закладкой в агрессивные среды партия образцов была испытана на прочность при сжатии в водонасыщенном состоянии. Контрольное значение прочности уртитов как среднее из 20 образцов, составляло 150 МПа.

В таблице 2 приведены результаты изменения массы и прочности образцов уртита после 6 месяцев испытаний в лабораторных агрессивных средах.

Таблица 2. Изменение массы и прочности образцов уртита.

Table 2. Change of weight and strength of samples of urtite.

\begin{tabular}{|c|c|c|c|c|c|c|c|c|}
\hline \multirow{3}{*}{ № среды } & \multicolumn{8}{|c|}{ Средние значения потери уртитов } \\
\hline & \multicolumn{4}{|c|}{ По масcе } & \multicolumn{4}{|c|}{ По прочности } \\
\hline & $\mathrm{m}_{0}, \Gamma$ & $\mathrm{m}_{0.5}, \Gamma$ & $\Delta \mathrm{m}_{0.5}, \Gamma$ & $\Delta \mathrm{m}_{0.5}, \%$ & $\mathrm{R}_{0}, \mathrm{M \Pi а}$ & $\mathrm{R}_{0.5,}, \mathrm{M \Pi а}$ & $\Delta \mathrm{R}_{0.5,} \%$ & Коэф. размягч. \\
\hline I - дист. вода & 188.80 & 188.75 & 0.05 & 0.03 & 150 & 144 & 4.0 & 0.96 \\
\hline $\mathrm{II}-\mathrm{Cl}^{-}$ & 191.13 & 191.06 & 0.07 & 0.04 & 150 & 142 & 5.3 & 0.95 \\
\hline $\mathrm{III}-\mathrm{SO}_{4}^{2-}$ & 196.30 & 196.23 & 0.07 & 0.04 & 150 & 141 & 6.0 & 0.94 \\
\hline $\mathrm{IV}-\mathrm{NO}_{3}^{-}$ & 188.52 & 188.43 & 0.09 & 0.05 & 150 & 141 & 6.0 & 0.94 \\
\hline
\end{tabular}

Приведенные результаты показали, что через 6 месяцев наблюдается тенденция небольшого снижения массы во всех жидких средах, в том числе и в дистиллированной воде. Максимальные потери массы образцов-кубиков из уртитов за полгода составили $0.09 \%$ в азотнокислой среде и не превысили допустимые $0.15 \%$.

Результаты прочностных испытаний образцов уртитов показали, что в течение 6 месяцев испытаний во всех жидких средах у пород наблюдалось незначительное снижение показателей прочности. Наибольшее снижение прочности уртитов наблюдается у образцов, хранившихся в сернокислой и азотнокислой средах (6.0 \%), меньше - в дистиллированной воде (4.0 \%). Максимальное снижение прочности обеспечивает коэффициент размягчения пород $\mathrm{K}_{\text {разм. }}=0.94$ при допустимом $\mathrm{K}_{\text {разм. }}=0.8$, что позволяет судить о достаточной стойкости уртитов в жидких агрессивных средах. Визуальных признаков разрушения образцов ни в одной из сред не наблюдалось.

Исследование микроструктуры уртитов, подвергшихся воздействию агрессивных сред, проводилось на поляризационном микроскопе Axioplane, оснащенного блоком видеорегистрации и фо- 

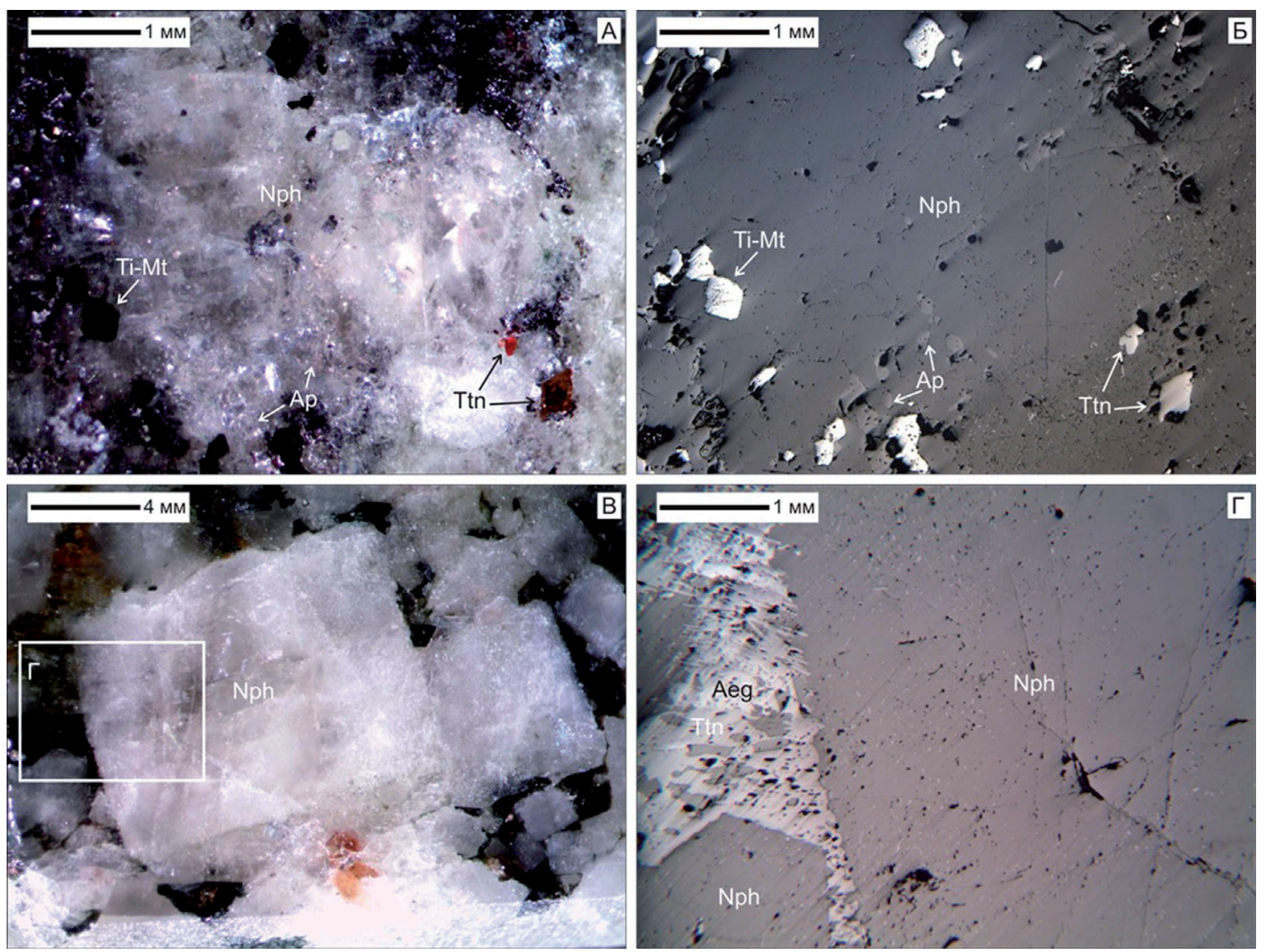

Рис. 2. Нефелин (Nph) до воздействия реагентов (А-Б) и после воздействия соляной кислоты (В-Г). A, В - макрофото; Б, Г - снимки в отраженном поляризованном свете. Aeg - эгирин; Аp - апатит; Тi-Mt - титаномагнетит; Ttn - титанит.

Fig. 2. Nepheline (Nph) before reagent action (A-Б) and after hydrochloric acid action (B-Г).

A, B - macrophoto; B, Г - reflected polarized light images. Aeg - aegirine; Ap - apatite; Ti-Mt - titanomagnetite; Ttn - titanite.

томикроскопе UltraPhot-3 с видеоокуляром ToupCam-3.1 в ГИ КНЦ РАН. Изучение минералов в отраженном и проходящем поляризованном свете осуществлялось на шлифах и полированных аншлифах уртитов, хранившихся 6 месяцев в жидких средах. В качестве примера на рисунке 2 приведены фото основного минерала уртитов - нефелина до воздействия реагентов и после воздействия в течение 0.5 года раствора соляной кислоты.

Под микроскопом видно, что нефелин обладает белой, серовато-белой окраской (рис. 2, А, В); минерал трещиноватый (рис. 2, А-Г). Формы выделений представлены в основном идиоморфными кристаллами, реже ксеноморфными кристаллами и сростками (рис. 2, А). Исследования в отраженном и проходящем свете показали, что нефелин насыщен мелкими (первые десятки микрон) включениями эгирина (что придает ему зеленоватый оттенок), апатита, титанита. Также эти минералы, более крупного размера, наблюдаются в краевых частях кристаллов нефелина (рис. 2, Б). Изучение нефелина, подвергшегося воздействию реактивов, не выявило существенных различий от его первоначального вида. Например, на рисунке 2 (В-Г) показан кристалл нефелина после воздействия соляной кислоты. Поверхность среза достаточно гладкая, небольшая пористость может быть связана с дефектами полировки. Границы с другими минералами четкие, на границах и в трещинах в нефелине не наблюдается следов коррозии или вторичного минералообразования. То же характерно и для других минералов, ассоциирующих с нефелином - титанита, апатита, эгирина, титаномагнетита

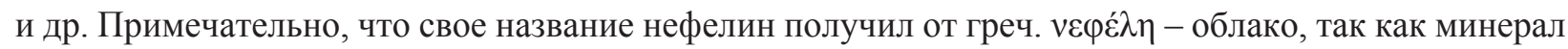
растворяется в сильных кислотах (в том числе - соляной), с выделением студенистой массы кремнезема (Бетехтин, 2007). Однако в данных образцах следов растворения минералов не наблюдается. 
Аналогичным образом ведут себя нефелин и породообразующие минералы в образцах, изготовленных из уртитов, находившихся под действием других жидких сред. Таким образом, микроскопическими исследованиями установлено, что в образцах уртитов после 6 месяцев хранения в агрессивных средах, признаков коррозии не обнаружено.

В целом, испытания образцов из уртита в жидких агрессивных средах показали, что данные породы являются достаточно стойкими по отношению ко всем использованным жидким средам.

Исследование коррозионной стойкости заполнителей из уртитов проводилось в условиях воздействия 4-х указанных выше жидких сред на щебне фракции 10-20 мм. Для определения потерь массы в каждую среду были заложены по 6 проб первоначальной массой в сухом состоянии около 400 г. Первоначальные значения дробимости щебня из уртита были определены как среднее из 6 параллельных испытаний. Средние значения дробимости уртитов составляли $16.15 \%$.

В таблице 3 представлены результаты изменения массы и дробимости щебня за первые 0.5 года испытаний в жидких средах.

Таблица 3. Изменение массы и дробимости щебня из уртита.

Table 3. Change of weight and the crushability of crushed stone from urtite.

\begin{tabular}{|c|c|c|c|c|c|c|c|}
\hline \multirow{3}{*}{ № среды } & \multicolumn{7}{|c|}{ Средние значения потери щебня } \\
\hline & \multicolumn{4}{|c|}{ по массе } & \multicolumn{3}{|c|}{ по дробимости, \% } \\
\hline & $\mathrm{m}_{0}, \Gamma$ & $\mathrm{m}_{0.5}, \Gamma$ & $\Delta \mathrm{m}, \Gamma$ & $\Delta \mathrm{m}, \%$ & Др 0 & Др $p_{0.5}$ & $\Delta Д p$ \\
\hline $\mathrm{I}-$ д. в & 400.00 & 399.25 & 0.75 & 0.19 & 16.15 & 17.65 & 1.5 \\
\hline $\mathrm{II}-\mathrm{Cl}^{-}$ & 400.18 & 399.52 & 0.96 & 0.24 & 16.15 & 18.45 & 2.3 \\
\hline $\mathrm{III}-\mathrm{SO}_{4}^{2-}$ & 400.00 & 398.61 & 1.39 & 0.35 & 16.15 & 18.75 & 2.6 \\
\hline $\mathrm{IV}-\mathrm{NO}_{3}^{-}$ & 400.02 & 398.28 & 1.74 & 0.43 & 16.15 & 18.25 & 2.1 \\
\hline
\end{tabular}

Результаты испытаний показали, что через 6 месяцев хранения во всех жидких средах у исследуемых проб щебня имеются определенные потери массы. Наиболее агрессивной средой для заполнителей является раствор с повышенным содержанием ионов $\mathrm{NO}_{3}{ }^{-}-\Delta \mathrm{m}=0.43 \%$ при допустимых $5 \%$. По сравнению с показателями, полученными на параллельных образцах в дистиллированной воде, потери массы в агрессивных средах различаются не более, чем на 0.24 \%. На этом основании можно сделать вывод о достаточной стойкости щебня из уртита в исследованных жидких средах.

Сравнивая показатели дробимости проб щебня, полученные для каждой агрессивной среды через 6 месяцев испытаний, с исходными значениями, видно, что показатели дробимости, т.е. потери по массе при испытании щебня на сжатие в цилиндре, во всех средах увеличились, достигнув в сернокислой среде максимального значения потери массы при дробимости в $2.6 \%$. Дробимость проб щебня, помещенных в дистиллированную воду, не отличалась от дробимости проб щебня из других агрессивных сред более чем на 1.1 \%. Несмотря на потери, щебень во всех средах через 6 месяцев испытаний показал ту же марку по прочности, что и до испытаний (М1000). На этом основании можно сделать вывод о стойкости щебня из уртита во всех лабораторных жидких средах. Дальнейшие коррозионные испытания уртитов, заполнителей из уртитов и бетонов на их основе позволят сделать более точные выводы для научного обоснования вовлечения в производство техногенных месторождений апатито-нефелинового сырья.

\section{Литература}

1. Белогурова Т.П., Крашенинников О.Н. Утилизация вскрышных пород Хибинских апатитонефелиновых месторождений в строительстве // Строительные материалы. 2004. № 6. С. 32-35.

2. Бетехтин А.Г. Курс минералогии: учебное пособие. М.: КДУ. 2007. 721 с.

3. Доклад о состоянии и об охране окружающей среды Мурманской области в 2017 году. Мурманск: Правительство Мурманской области. 2017. 165 с. Интернет ресурс: https: // gov-murman.ru/region/environmentstate. 